\title{
Implementation of SExI-FS (Spatially Explicit Individual-based Forest Simulator) Model using UAV Aerial Photo Data Case Study: Jatinangor ITB Campus
}

\author{
Aminah Kastuari ${ }^{1 *}$, Deni Suwardhi ${ }^{1}$, Himasari Hanan ${ }^{2}$, Ketut Wikantika ${ }^{1}$, Agung Budi Harto ${ }^{1}$, RiantiniVirtriana ${ }^{1}$, Shafarina \\ Wahyu Trisyanti ${ }^{1}$ \\ ${ }^{1}$ Department of Geodesy and Geomatic Engineering, Faculty of Earth Sciences and Technology, Institut Teknologi Bandung, Bandung, \\ Indonesia \\ ${ }^{2}$ Architectural History, Theory and Criticism Research Group, School of Architecture, Planning, and Policy Development, Institut \\ Teknologi Bandung, Bandung, Indonesia
}

\section{ARTICLE INFO}

Article history:

Received February 10, 2018

Received in revised form July 1, 2020

Accepted July 7, 2020

\section{KEYWORDS:}

3D city model,

dynamizer,

3D spatial-temporal,

CityGML,

SeXI-FS

\begin{abstract}
Landscape architecture affected by interaction between built and natural environment such as vegetation. Nowadays, landscape architects are using 3D city models for simulations, which requires highly dynamic and time-varying attributes. 3D city modelling structure has been standardized by CityGML, although researches that are related to the storing of dynamic data had been conducted for the past years, it has not been supported by any standard until this very moment. In dynamizer, it is added as a data structure into a CityGML structure that is already existed, although the existing structure is a static one. Kolbe's research on dynamic data using CityGML called dynamizer could use the spatial data in more dynamic way by changing its geometric, thematic, or appearance data, but its purpose is not specific for trees or vegetation. In this paper, a method of simulating the vegetation growth using SeXI-FS will be discussed to show the dynamic changes that happen in vegetation as part of the dynamic changes in landscape architecture. The result of this research will be used to address the importance of information on vegetation by studying its changes in Jatinangor ITB Campus and as initial research to build dynamizer in CityGML for landscape architecture.
\end{abstract}

\section{Introduction}

There are two major components on landscape information, which are (1) information and knowledge about sites (terrain, ground conditions, weather, microand macro-climate, and so forth), and (2) information and knowledge about landscape objects ("soft" materials such as vegetation, and "hard" materials of built objects) (Zahradkova and Achten 2013).

Vegetation has its own functional use, apart from what had been known for its aesthetic use. Vegetation could perform other functions in landscape. Vegetation could function as noise barrier and climate control. It also has architectural use, for example to form wall, canopies, or floor. And last but not least, vegetation could also has function from engineering aspect, for example as pollution control, wind breaker, or to soften sun's glare (Sannuta 2013).

\footnotetext{
* Corresponding Author

E-mail Address: aminah.kastuari@gmail.com
}

Forests are facing rapid land use changes caused by multiple social, cultural and economic factors. There is an overall concern on the prevailing land use practices, such as shifting cultivation and extraction of forest materials as agents of forests losses, but also new, emerging land uses are threatening tropical forests. Understanding of the long-term development and driving forces of vegetation changes are needed, especially at local levels where many decisions on policies of vegetation and land uses are made (Käyhkö et al. 2011).

As part of the landscape changes, it is important to analyse the changes on the vegetation, which also consists the changes of the trees or the greenery factor of the landscape.

Vegetation is all plants from a region that come from that region itself or coming from outside that region, which includes trees, shrubs, bushes, and grass (PerMen PU No:05/PRT/M/2008). Vegetation has an important role in an urban area. As mentioned in IM-Tree-Towards an Information Model for an Integrated Tree Register 
(Rip and Bulens 2013), trees are vital aspect that their health had to be taken care of so they do not caused any endangerment, such as falling branches or falling trees. For that reason, a data that filled with information on those trees has to be (Trisyanti 2017).

$3 \mathrm{D}$ visualization and spatial analysis, along with remote sensing and Geographical Information System (GIS) could help the evaluation and decision-making process as a tool to design landscape in the urban areas (Martínez-Graña and Rodríguez 2016).

Changes in an urban area, especially in its rapid changes on the population and economy is making impact on the urban growth. These also could affected how landscape architecture is designed and planned (Cheng and Masser 2004). Understanding on rapid urban growth is needed in order to achieve sustainable land management and urban development planning. Another example of use for dynamic data model in landscape could also caused by the changes in physical landscape changes, such as estimating the damages that caused by natural disaster or human caused disaster (i.e. hurricane, earthquake, flooding, fire) or for the purpose of reconstruction, which done by analysing data from multiple sources, some of which are 3D spatialtemporal data. The dynamic on vegetation growth is also another factor for urban growth.

As mentioned previously the vegetation is very dynamic element of the design. Its changes during the whole life-cycle (size, shape) as well as its seasonal cycle is important as part of the landscape changes, therefore it had to be predicted. These are the factors of vegetation changes (Zahradkova and Achten 2013).

1. Development/growth: Youth, Period of fertility, Period of death.

2. Reshaping: compact design changes in the last stage to the irregular shapes.

3. Seasonal cycle-behaviour, requirements, and appearance throughout the aspects of spring, summer, autumn, winter.

The development of spatial-temporal models have been varied, most of which have been implemented for managing 2D spatial-temporal (2D space plus 1D time) objects. 2-dimensional (2D) GIS is not able to describe the earth in accordance with reality or close to reality, because the earth is a three-dimensional field. When the temporal dimension is taken into account, elevations of many 3D objects and phenomena do change over time (Jing 2009).

The dynamic changes of vegetation could be simulated using SeXI-FS software. The SExI forest simulator focuses on tree-tree interactions in a mixed multi-species agroforestry. The high level of structural complexity of such traditional agroforestry systems defies classical forestry approaches when it comes to optimizing management practices (Harja and Vincent 2008).

The model uses an object-oriented approach where each tree is represented by an instance of a generic class of tree. The simulated object trees, mimicking real trees, interact through modifying their neighbours' environment. These modifications are mediated through two major resources: space and light. A 3D representation of a one-hectare plot of forest serves as the grounds for the simulation of this competition (Harja and Vincent 2008).

Model sensitivity tests confirm the importance of the parameters related to tree geometry. This stems from the fact that competition is simulated by means of spatial interactions, so that anything that alters either the shape, the size, or the relative position of the trees have direct impact on the outcome of the competition and therefore on the growth dynamics. These elementary influences are usually straightforward but their effect at different times and scales are difficult to predict without simulations because of the numerous feedback loops at work and the non-linear dynamics of the system (Harja and Vincent 2008).

On SeXI-FS, the potential diameter increment of each tree is calculated using the first derivation of Chapman-Richards function, with dbh is diameter at breast height, will be explained in chapter 2 :

$$
\left(\mathrm{dbh}=\mathrm{dbh}_{\max } \mathrm{x}\left(1-\mathrm{bxe} \mathrm{e}^{(-\mathrm{kxt})}\right)^{\mathrm{c}}\right)
$$

Actual growth is then derived from this calculation after addition of other environmental effects and species sensitive response (ICRF and IRD 2008).

Enhanced height growth is achieved at the expense of dbh increment. Assuming that total stem biomass scales isometrically with the product of stem cross sectional area and tree height, the maximum possible height increment is then limited by actual dbh increment (Harja and Vincent 2008).

\section{Materials and Methods}

The data that is used as input is aerial photo from Jatinangor Campus ITB from 2011, and the data that is being used as comparison is aerial photo from Jatinangor Campus ITB from 2016 (Figure 1).

For the data collecting until the needed information on the trees that are used as input in SExI-FS for simulation, as mention below, it is adapted from (Trisyanti 2017):

1. Data acquisition. The data is collected using UAV Photogrammetry using camera that is mounted in an unmanned aerial vehicle. 


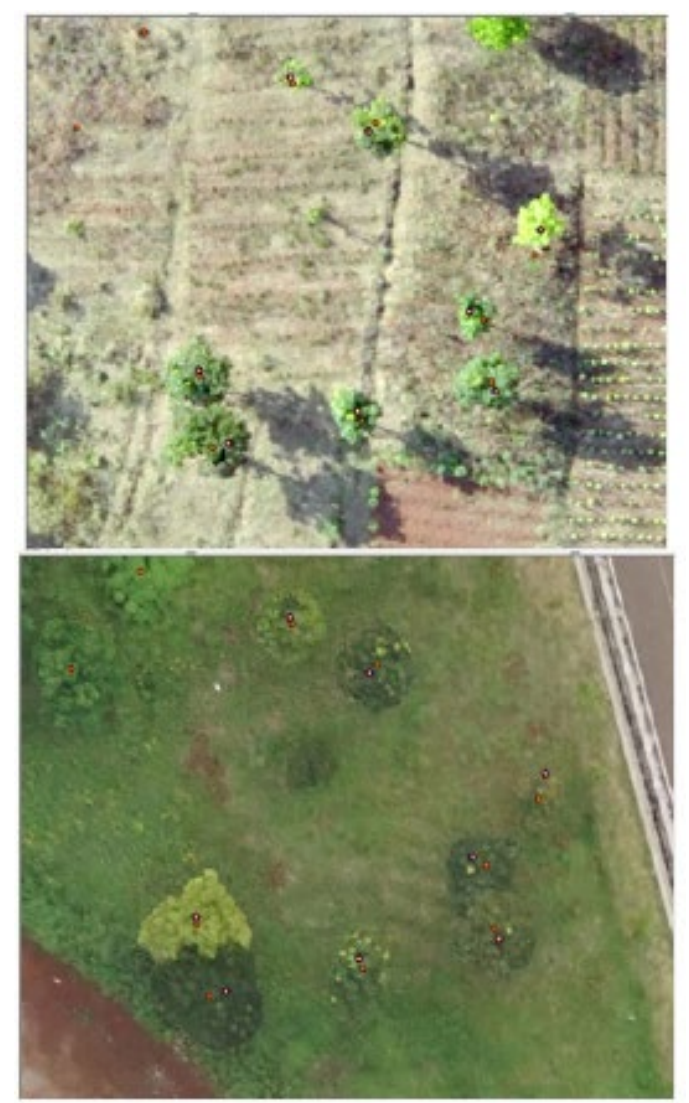

Figure 1. Aerial photo for the trees in the same location, the above picture was taken in 2011 and the below one was taken in 2016

2. Data processing and 3D Modelling. The UAVPhotogrammetry data then being processed using Agisoft Photoscan Professional software. Global Mapper is also used for the resampling process on the point cloud to get rid of the points that are not needed.

3. Segmentation. Segmentation is done later on to separate the points into parts that have same characteristic. Segmentation is done by doing digitization for the tree objects, by adding points coordinate of the tree position and circle polygon for the tree crown estimation. The result of this digitization is vector data of the trees in Jatinangor ITB Campus.

4. Classification. The classification that is done to the vegetation is using manual method by looking at the orthophoto. The added information of the species of each trees are added as an attribute using ArcGIS.

5. Visualization. The detail level of vegetation that is needed in landscape architecture depends on the planning scale that will be delivered. Each Level of Details (LoD) could be seen in Figure 2.
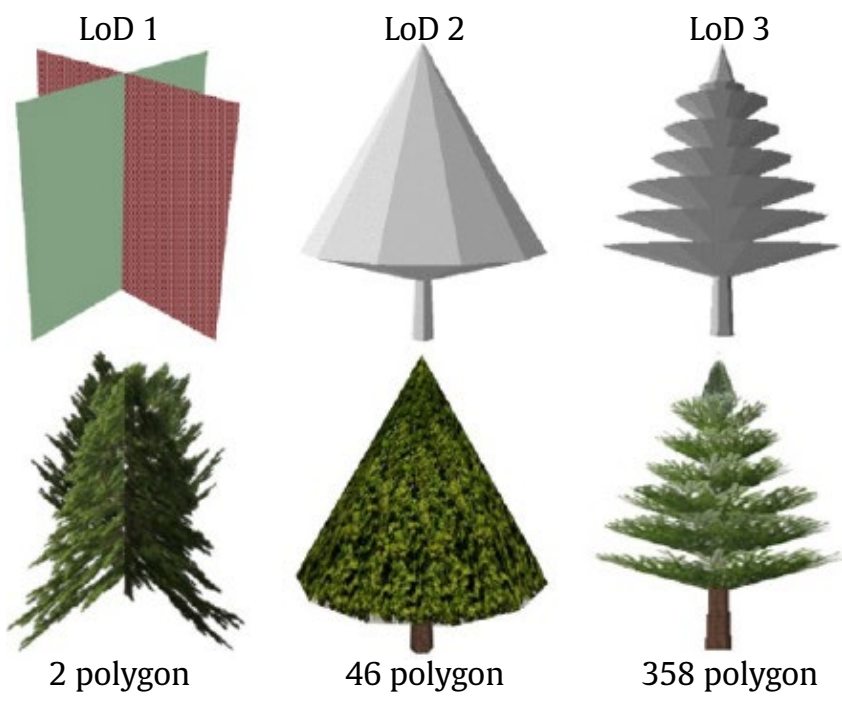

Figure 2. Visualization comparison between LoD 1, 2, and 3 for coniferous tree without texture (above) and with additional texture (below) (Trisyanti 2017)

CityGML defines the classes and relationship between topographical objects that related to city or domain model by taking geometric, topology, semantic, and behaviour into account. One of the characteristic that CityGML has is multi-scale modelling. For that reason, CityGML could differentiate the level of details for objects, especially for buildings, which is called Levels of Detail (LoD) until five levels (0-4) (Trisyanti 2017).

Dynamic properties within 3D city models will be advancement and beneficial for smart city applications. In order to achieve that objective, a new concept called Dynamizer was proposed, which allows modelling and supporting dynamic properties within 3D city models. The approach allows representing dynamic data in the form of time series and provides a method to inject them into the static attributes of city models (Chaturvedi and Kolbe 2016).

Dynamic data could be implemented in these properties of city object (Chaturvedi and Kolbe 2016):

1. Spatial Information (Geometry \& Topology)

- $\quad$ Extent and form: e.g. retrofitting, extension,(partial) demolition of sites; plant growth; watercourse during flooding

- $\quad$ Location: e.g. for movable objects like vehicles or persons the position and orientation

2. Appearance Information

- $\quad$ Colour, texture: e.g. change of the appearance of building facades within an RGB or Thermal IR image over the day 
3. Semantic Information

- $\quad$ Thematic data like e.g. electrical power consumption of a building; room temperature; traffic density in a road; evaporation of a group of trees

In Zahradkova's research, they are using these properties and attributes to describe the plants: height, perimeter of canopy, perimeter of a trunk, classification in the meaning of family- genus- species- cultivar, to state if the plant is deciduous or evergreen, the aspect of season (mainly to state the existence and colour of the leaves), the age of the plant and its habitus an finally for most efficient work with the objects the detailing and the way of graphic appearance (Zahradkova and Achten 2013).

In SeXI-FS these attributes are used in order to visualized the trees using related software (Figure 3):

1. id: identity number of related tree

2. $\mathrm{X}$ : the $\mathrm{x}$ position of the tree base $(\mathrm{m})$

3. $\mathrm{Y}$ : the $\mathrm{y}$ position of the tree base $(\mathrm{m})$

4. Species: the species label, if the label is match with the one in the species list then it will be linked, otherwise new species definition will be created

5. DBH: Diameter at breast height. DBH refers to the tree diameter measured at 4.5 feet above the ground. A tree's diameter at your breast or chest height is the most common tree measurement made on a tree by tree professionals. (Nicks 2017)

6. Height: the height of the tree (m)

7. Cr_depth: crown depth

8. Cr_curve: crown curve (m)

9. Cr_radius: crown radius in vertical projection, can be more then one value separated by semicolon $(\mathrm{m})$. The illustration of crown radius is shown in Figure 4.

Measuring forests with LiDAR

Direct measurements include:

- Stand density

- Tree height

- Crown width

- Crown length
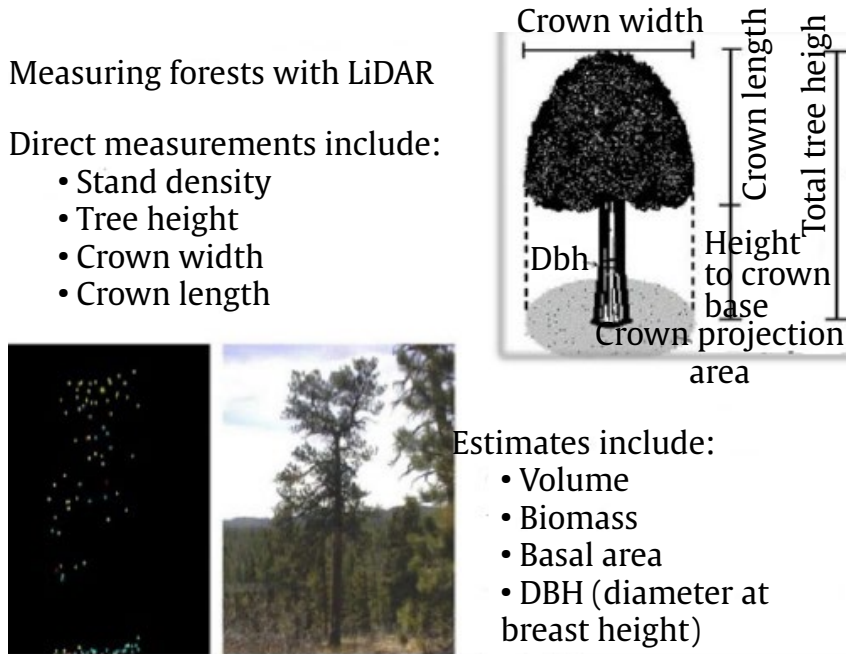

Estimates include:

- Volume

- Biomass

- Basal area

- DBH (diameter at

breast height)

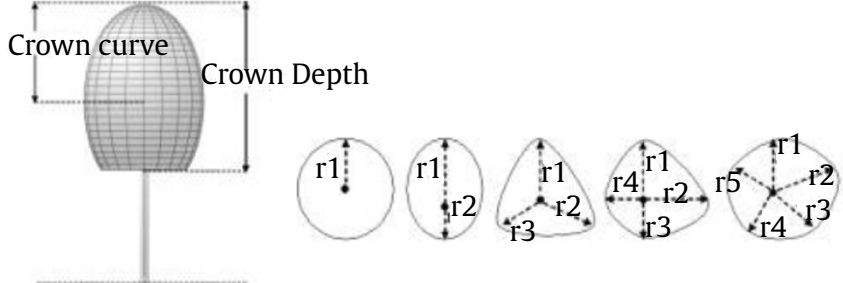

Figure 4. lustration of crown curve, depth, and radius

$\mathrm{x}, \mathrm{y}$ coordinates, height, $\mathrm{cr} \_$radius are obtained from the digitizing of the aerial photo. Since DBH, cr_depth, and cr_curve could not be obtained only from aerial photo, it is assumed for the purpose of this research. The species of the trees are not classified yet so they are assumed that they all are coming from the same species.

The crown depth is assumed by each species ratio to its height, in this research ratio of 0.7 of tree height is used. The DBH is assumed by a ratio of the diameter of the crown radius, based on its individual species, in this case a ratio 0.05 of the crown radius is used. The cr_curve is assumed by each species ratio to the crown depth, in this research, a ratio 0.7 between crown depth and crown curve is used. The illustration of crown curve and crown depth is shown in Figure 4.

For the first step, the attributes mentioned above are used as input in the SeXI-FS software in tab delimited text format. The coordinates have to be in local coordinate. The input data then being constructed to see the visualization in 2 dimensional for then it is visualized in 3 dimensional. The constructed plants result later on being simulated in the software, and as the data want to be compared to 2016 data, and the input data is 2011, the amount for year to simulate is 5 years. The visualization of trees from 2011 that were simulated in SeXI-FS could be seen in Figure 5.

\section{Results}

The result table of height comparison from the simulation from SeXI-FS could be seen in the following Table 1 and 2.

As could be seen from both of the table shown before, based on the height and crown radius alone, there are some inconsistency on the prediction of the trees, from data 2011 that simulated for 5 years and the results of the data that is taken on 2016 that could be caused by these factors:

1. Digitization on each data, different person that digitize the data cause different perception on interpreting the trees. If the trees are in groups, the data interpretation is harder because there will be differences in the height and location for the same tree.

Figure 3. Illustration of attributes that are used in SExI-FS 

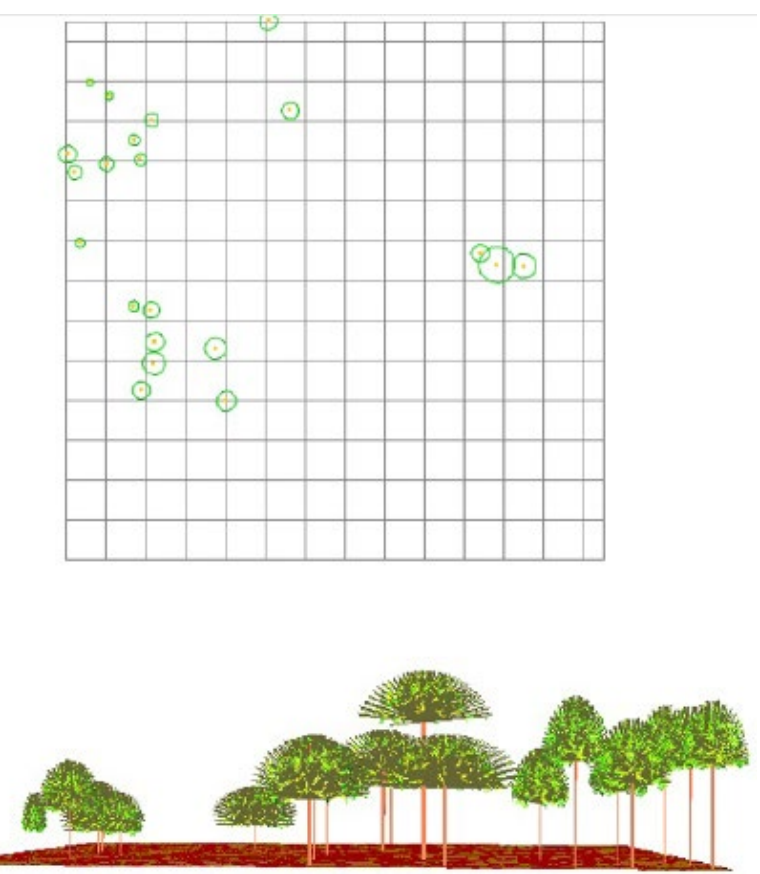

Figure 5. The visualization of trees from 2011 in 2D (left) and 3D (right)

2. The assumption that made on each trees for species, DBH, crown depth, and crown curve. Based on Eq. 1.1. the enhanced height growth is achieved at the expense of dbh increment, since the dbh were assumed, it could not describe the accurate tree growth simulation from the software. Other reason is since the species for each trees were assumed as the same species, it also could not describe the tree growth accurately since each species of trees might have different ability of how much it might grow overtime.

As seen on Figure 6, Dynamizer is a new feature type which is a sub-class of AbstractCityObject. In addition, AbstractDynamizerCityObject extends the class AbstractCityObject by the additional association dynamizer. That means that all city objects such as buildings, roads, vegetation etc. can now include links to their respective dynamizer features. attributeRef refer to a specific property of a static CityGML feature which value will then be overridden or replaced by the (dynamic) values specified in the 'Dynamizer' feature. startTime and endTime denote time span for which Dynamizer provides dynamic values. Dynamizer composes of AbstractTimeseries, which allows to represent time-variant values in different and generic ways (e.g. Timeseries, Sensor observations etc.).
Table 1. Comparison of tree heights (in meters)

\begin{tabular}{rrrr}
\hline id & 2011 & Predicted 2016 & 2016 \\
\hline 899 & 1.639404 & 2.97168 & 10 \\
1839 & 5.753357 & 8.639331 & 5 \\
1846 & 0.577881 & 1.437269 & 18 \\
1847 & 3.015625 & 4.709695 & 24 \\
1990 & 6.122803 & 8.733632 & 15 \\
1999 & 9.894053 & 13.655525 & 14 \\
2035 & 10.152465 & 13.359309 & 8 \\
2247 & 7.032776 & 9.992104 & 15 \\
\hline
\end{tabular}

Table 2. Comparison of tree crown radius (in meters)

\begin{tabular}{rlrr}
\multicolumn{1}{l}{ id } & 2011 & Predicted 2016 & \multicolumn{1}{c}{2016} \\
\hline 899 & 1.824953 & 4.11396 & 2.743166 \\
1839 & 2.408991 & 4.240739 & 7.637244 \\
1846 & 2.816731 & 5.87101 & 5.319324 \\
1847 & 2.190071 & 4.126484 & 5.093578 \\
1990 & 2.176041 & 3.654572 & 5.120189 \\
1999 & 2.123864 & 4.466609 & 2.77108 \\
2035 & 2.221421 & 3.105435 & 2.653927 \\
2247 & 2.346247 & 3.969047 & 2.38959 \\
\hline
\end{tabular}

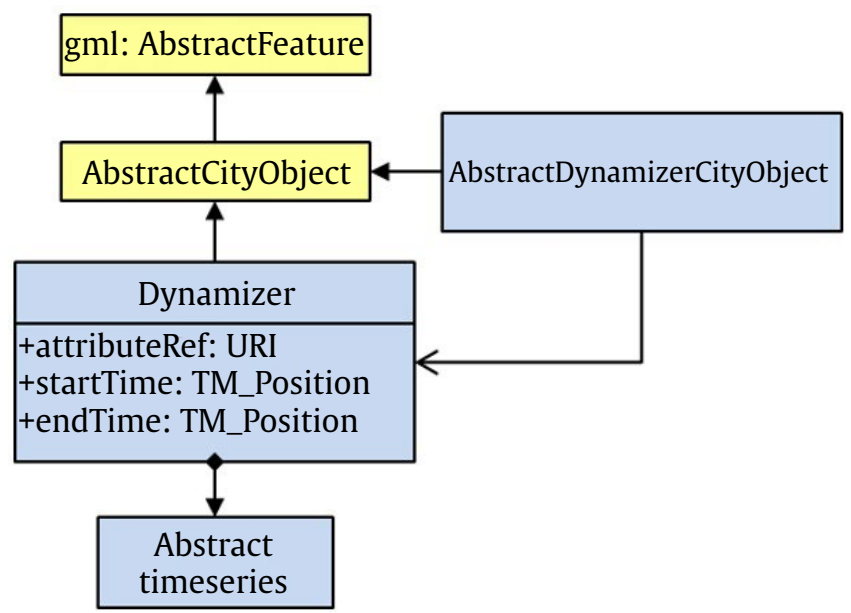

Figure 6. Conceptual model of implementation on Dynamizer for vegetation. Newly introduced classes are shown in blue. Classes shown in yellow are from GML and CityGML respectively (Chaturvedi and Kolbe 2016)

\section{Discussion}

The uses of 3D GIS are already being developed in landscape architecture. Conventional two-dimensional GIS is not able to provide an overview of existing conditions that is used in landscape designs realistically and systematically, the architecture had to use their imagination to determine the existing condition. 
The researches that proposed model that designed to provide reasonable and formal descriptions of 3D spatial-temporal objects to capture their spatial characteristics, temporal properties, dynamic behaviors and attributes are ongoing research. Although already the researches already covered the dynamic data model for 3D spatial-temporal objects, they are still lacking on how to store the geometry data, specifically by using CityGML.

Trees or vegetation is chosen to be described in dynamic spatial data because of their complexity in topology and geometry, and it is one important part of dynamic data in landscape architecture.

SeXI-FS shows prove that dynamic data for vegetation does exists and as important as other aspects of landscape architecture data. It also shows that the vegetation is indeed a geometrical and spatial data. The SeXI-FS results are satisfying enough for prediction, but that does not mean that the results will be the same with factual data because there are many factors that affecting the tree growth. There has to be another data sampling that is more thorough in order to have more accurate data as input.

The result of simulation in SeXI-FS is intended to be used for further research to see the tree growth pattern each year, in order to have the data spatial structure to be stored in CityGML. The dynamic data then could be used in Dynamizer. The related research that using CityGML as data storage and visualization was done until LoD 3, in order to have more accurate presentation of the tree growth and visualization, further research should be done until LoD 4 . The CityGML dynamizer will be covered by discussing the part of semantic, topology, appearance, and geometry of trees or vegetation.

\section{References}

Chaturvedi K, Kolbe TH. 2016. Integrating dynamic data and sensors with semantic 3D city models in the context of smart sities. Understanding Spatial and Temporal Processes of Urban Growth: Cellular Automata Modelling V-2/W1:31-38.

Cheng J, Masser I. 2004. Understanding spatial and temporal processes of urban growth: cellular automata modelling. Environment and Planning B Planning and Design 31:167-194.

Harja D, Vincent G. 2008. Spatially Explicit Individualbased Forest Simulator-User Guide. Bogor: World Agroforestry Centre (ICRAF) and Institut de Recherche pour le Développement (IRD).

ICRF, IRD. 2008. SeXI-FS: Spatially Explicit Individualbased Forestry Simulator. Available at: http://www. worldagroforestry.org/output/sexi-fs-spatiallyexplicit-individual-based-forest-simulator [Date accessed: 6 October 2016]

Jing L. 2009. A Constraint-Based Model for 3D Spatial-Temporal Data (Vol. 1). Fairfax: George Mason University.

Käyhkö N et al. 2011. Dynamic land use and land cover changes and their effect on forest resources in a coastal village of Matemwe, Zanzibar, Tanzania. Land Use Policy 28:26-37.

Martínez-Graña AM, Rodríguez VV. 2016. Remote Sensing and GIS Applied to the Landscape for the Environmental Restoration of Urbanizations by Means of 3D Virtual Reconstruction and Visualization (Salamanca, Spain). Int J Geo-Inf 5:1-24.

Nicks S. 2017. What is Diameter Breast Height? Available at: https://www.thoughtco.com/what-is-diameterbreast-height-1341720 [Date accessed: 12 September 2017]

Rip FI, Bulens J. 2013. IM-Tree. Towards an information model for an integrated tree register. 16th AGILE Conference on Geographic Information Science.

Sannuta S. 2013. Slideshare. Available at: https://www. slideshare.net/sweetsaimaiqbal/vegetation-inlandscape [Date accessed: 10 April 2017]

Trisyanti SW. 2017. Pemetaan Lanskap 3D Tematik NonBangunan: Vegetasi (Studi Kasus: Kampus ITB Jatinangor). Bandung: Institut Teknologi Bandung.

Zahradkova V, Achten H. 2013. Landscape Information Model: Plants as the components for information modelling. Stouffs, Rudi and Sariyildiz, Sevil (Eds.). Computation and Performance-Proceedings of the 31st eCAADe Conference. 2. Delft: Delft University of Technology. pp. $515-253$. 